LITERATURE AND EPIDEMIOLOGY

\title{
Saramago's All the Names and the epidemiological dream
}

\author{
Naomar Almeida-Filho
}

J Epidemiol Community Health 2004;58:743-746. doi: 10.1136/jech.2003.013979

Language is crucial for all established scientific disciplines in contemporary society, particularly epidemiology. Portuguese writer Saramago wrote All the Names, a book about the Conservatoria, a gigantic registry that stores the whole life of an entire population. A parallel is made with the first social observatories that used entire populations for systematic observation, permitting the development of epidemiological methodology. Such "epidemiological dream" almost became true in virtual form with the introduction of electronic data processing. The central thesis of this paper is that Saramago's Conservatória allegory might be interpreted as akin to the virtual world construed by epidemiological science. Specifically, it is about abstract realities (or theoretical environments) that by definition are necessary for the process of scientific inquiry, particularly when oriented by knowledge production through observational strategies. Reading Saramago, the epidemiological virtualscape may be envisaged, more imaginary than it is usual to imagine and more real than it is usual to realise.

Correspondence to:
Dr N Almeida-Filho,

Instituto De Saude

Coletiva, Universidade

Federal Da Bahia, 40.110-

170 Salvador-Bahia,

Brazil; naomar@ufba.br

Accepted for publication 1 March 2004
S cientific and technological achievements are historical products of human society and culture. ${ }^{12}$ Beyond its material and economic dimensions, modern science is engendered by the never ending construction of a tremendously complex set of linguistic devices-images, signs, meanings, discourses, and languages. ${ }^{3}$ The language matter is therefore crucial for all established scientific disciplines in contemporary society.

For epidemiology today, language is even more central because the "society of risk" we live today continuously requires the discipline to give more and better answers to the enigma of health. ${ }^{5}$ The continuous effort of our scientific discipline to redefine and reshape itself to cope with endless "epidemiological riddles" does not bring another trivial demonstration of how knowledge, subject to determinations of the real, historical world, is constituted by social practices called science. ${ }^{126}$ It rather provides, indeed, a demonstration exactly of the opposite: how language may be considered as a crucial, irreplaceable tool for the construction of scientific worlds. ${ }^{67}$ This proposition includes, of course, the world of epidemiological science. I know that it might sound strongly idealistic and even close to irrationalism, particularly for hard core epidemiologists used to handling real life epidemics, masses of patients, tons of registries, and huge population samples. However, before prompt reactions, allow me to explore further the basis of this argument with the help of one of the masterpieces of contemporary Portuguese literature, All the Names [Todos os Nomes], by José Saramago, Nobel Prize 1998.

\section{SARAMAGO'S ALL THE NAMES}

All the Names ${ }^{8}$ is a novel about the Conservatoria Geral do Registro Civil [General Office of Civil Registry] of a timeless town, located anywhere in Portugal-although it could be in Brazil, Spain, Cuba, or any other country of Latin-Iberian inheritance. The Conservatória is archetypical of traditional bureaucratic organisations, totally dependent on ancient rules of forgotten origin and unknown function. Faceless officers, rigorous and inflexible, almost ruthless, govern and haunt the sombre, conservative institution.

Chapter one of Saramago's book is entirely devoted to a detailed description of the institution's hierarchical structure and how it operates. The wide and rectangular main hall has eight desks for the scrivener's helpers, located near the front bar to attend the public, four desks for the scriveners, who oversee the helpers' work, then two for the officers, who supervise the scriveners, and isolated, centred in the background of the room, "lonely as it should be", the large and dark desk and chair of the chief, the conservador. The room furniture is wood solid, severe and sober, elegant, "arranged, naturally enough, according to a hierarchy, but since, as one would expect, it is harmonious from that point of view, it is also harmonious from the geometrical point of view, which just goes to show that there is no unsurmountable contradiction between aesthetics and authority" (page 2). ${ }^{8}$ A simple principle rules the work at the Conservatória: the maximum possible labour must be completed at each level and only a minimal amount can be passed on to the upper levels of the hierarchy, to guarantee the order, discipline, and dignity necessary for the civic responsibility of the Conservatória.

Most important for our purpose herewith is the architecture of the strange building; particularly the gigantic annex where the archives are installed and documents are filed. Five long rows of large stacks, from the floor to the ceiling, start right behind the conservador desk and proceed to the end of the building, unseen because of the enormous size of the construction and to the darkness in the back of the hall. "Obeying to the law of nature", archives and files are stored in two sections: the living and the dead. Documents regarding the living, from birth certificates to labour cards, baptism forms and marriage licences, school registration to diplomas and 
degrees issued, accidents and disease absence requests to retirement premiums, with all the names, all the due signatures, are filed in the first sections of the stack lines. The papers related to the dead, with death certificates clipped to their files when alive, are thrown into the farthest sections of the stacks.

As the number of dead people never ceases to increase, periodically the administration of the Conservatória orders the demolition of the back wall to have it rebuilt several metres ahead. The archive hall is now hundreds of metres long, without windows or any sort of holes for the best conservation of its contents. A balance between the number of files of the living and of the dead was achieved in the past, which has made it possible to absorb the small increase of the living population by physical compression and afterwards using thinner file covers. Newborns are filed in the beginning of the front stacks, pushing the older ones to the end of the rows, and further up, until reaching the top of the upper stacks. Those who died at any moment of their life cycles are transferred from the sections of the living to the very end of the long row of stacks of the dead. For obvious reasons, the living files are much better organised than the ones belonging to the deceased. Given the many efforts to expand the now immense room and giant stacks, numerous big piles of documents have been left in the hallways, blocking many of them, forming tracks and detours that together make the whole area a sort of dark, sinister maze. Before the enforced adoption of Ariadne's thread, a researcher on heraldic got lost "in the labyrinthine catacombs of the archive of the dead" (page 6). ${ }^{8}$

The Conservatória comprises the micro-cosmos of a whole municipality, encapsulating its entire population, present and past, living and dead. Each and every inhabitant of the anonymous town has a file in its archives, with all the names (parents, relatives, authorities, godparents, partners, etc) meticulously registered. This implies for all of them a parallel existence inside the cyclopean document base, with connections and networks between the files and the names, nurtured by the care and neglect of the scrivener's helpers. This is what gives these simulacra of real life beings a tragic autonomy in the inner space of the pathetic institution.

\section{THE EPIDEMIOLOGICAL DREAM}

The first generation of scientific leaders of our field tried to establish observatories for methodological exploration, selecting entire populations for systematic and continuous observation. ${ }^{9}$ Framingham, linked to the School of Public Health of Harvard University, is now famous for the discoveries in relation to cardiovascular risk factors. Other public health schools implemented similar observation sites, such as Hagerstown for Johns Hopkins University, Alameda County for the University of California at Los Angeles, and Evans County for the University of North Carolina, among others. ${ }^{10}$ The populations of these localities were monitored year after year; they had their health conditions scrutinised in detail, with periodical clinical and laboratory examinations, giving away fluid and tissue samples to be stored for future research. Such observatories fostered much of the development of research design and techniques of risk analysis that eventually became the paradigm of epidemiological methodology..$^{10}$

In addition to social, political, and economic reasons, we should consider a strong epistemological motivation behind initiatives such as Framingham, Hagerstown, Alameda County, and the like. At that time, epidemiology was still a young discipline struggling for self affirmation among the biomedical sciences of the mid-20th century.$^{9-11}$ The organisation of reduced models of real life health-disease dynamics was indeed one of the first strategies of epidemiology towards building a scientific object of its own. Modelling epidemiological systems using conservation units, registries, and biosample sets extracted from controlled populations represented an effort for production, storage, and analysis of population health data. This strategy is strikingly similar to Saramago's Conservatória, as both can be read as prototypes of physical analogues of society. None the less, the material limits of composition and size of such reduced real life models, as well as the psychological, social, political, and institutional constraints imposed by the daily reality of concrete populations, prevented these Conservatórias from becoming the research plexus much dreamed of by our founding fathers (see Greenwood's notions of "experimental epidemiology" and "epidemiological laboratory", circa 1930). ${ }^{12}$

The "epidemiological dream" almost became true with the introduction of massive electronic data processing in the late 1960s. Information technology made possible the implementation of digital analogues, rather than physical analogues, for modelling epidemiological realities. On the one hand, for the first time, it was feasible to organise datasets big enough to reproduce demographic structure and dynamics closer to real populations. On the other hand, it allowed for computerised data handling, which improved the production process of scientific knowledge by combining observational strategies with post hoc analytical control. ${ }^{9}$ When applied to human subjects for health research purposes, such strategies are based on the transformation of human groups and populations (and their biological and demographic structure and dynamics) into registry and data through processes of selection, coding, translation, and meaning compression. Theoretically, the outcome of such processes may consist of flexible models or artificial devices that allow for simulations, fragmentations, and reconstructions, which in practice ends up being the very sense of epidemiological analysis.

The process of observation and data production in laboratory or fieldwork is the only credible assurance of the link between study population or sample and concrete reality. It means that solely believing that the methodology used was rigorous and appropriate we can trust that database B that we analyse corresponds to (or has for reference) the population of the district $S$ or province P. Such a guarantee comes out of a subtle and complex negotiation process, almost a tacit term of compromise signed by the researchers, members of wider networks of discursive and institutional support. ${ }^{6}{ }^{11}$ Nevertheless, in large population studies, the team that performs field or laboratory tasks normally is not the same that will do data analysis and eventually will make sense of the information produced; in many instances, private research companies are subcontracted for data collection, and the only material thing the researcher handles is a dataset already in digital form.

Objectively, the only true populations with which epidemiologists deal in their concrete practice are the populations of their databases. The surveyed sample or cohort constitutes a digital simulacrum of a flesh and blood population, composed by simulacra of the members of the so called reference population. Concretely speaking, the locus of epidemiological research eventually consists of an abstract object, digital in nature, built by the daily practice of investigation, through gathering observations, coding data, and producing information. In this regard, it is a virtual interactive programmable environment roughly of the same nature of astrophysical or meteorological databanks. Despite obvious differences in the strategies, logistics and technologies involved, any research location is socially constructed by the daily practice of science. The loci of research activities may be well bounded and fixed locations (laboratories), unbounded but fixed locations (observatories), or unbounded 
and non-fixed locations (fields, sites, etc). In the particular case of epidemiological science, the field can be located wherever the multiple presence of a research team can apply data production tools and techniques, while the epidemiological laboratory may be entirely a "virtual reality" environment. Then the imagined fields, places, spaces, sites, and communities might become part of special "virtualscapes", artificial grounds useful for new experiences in conducting research, and furthermore for theory building, in epidemiology.

Let us take the "risk" concept as an illustration. As a researcher, the epidemiologist does not need to relate directly to suffering, affliction, illness, sickness, disease, pathology, and death but rather he/she questions observations, registries, data, information and knowledge, which are normally translated into parameters, estimates, and measurements of risk and risk correlates. One of the fundamental keystones of the scientific discourse of epidemiology, the risk concept has increasingly become an essential part of the language of health and biomedical sciences. ${ }^{11}{ }^{13-15}$ The concept of individual risk lies on a parallel stochastic dimension populated by virtual beings, subjects at risk, recognised by their probabilities to get sick and to cure or to die. ${ }^{14}$ Real people then may become pure "epidemiological profiles", configurations of risk factors, or risk configurations. The epidemiologist's concept of risk therefore implies a fictitious (but not fictional, at least before Saramago) virtual environment, ruled by parameters and functional norms that are analytically manipulated under a quite particular logic. The "epidemiological virtualscape" is structured as a matrix of risks, determined by risk functions, risk markers, risk factors, and risk behaviours.

\section{EPIDEMIOLOGY AS A POST-MODERN SCIENCE}

The central thesis of this paper is that Saramago's Conservatória allegory might be interpreted as akin to the virtual world construed by epidemiological science. Specifically, it is about abstract realities (or theoretical environments) that by definition are necessary for the process of scientific inquiry, particularly when oriented by knowledge production through observational strategies. Yet such a metaphorical operation is not exclusive of epidemiological science. Similar analogies may be applicable for the demographic, sociological, economical, and ecological worlds as made up by the respective scientific disciplines of demography, sociology, economics, and ecology. Or can someone still argue that "the environment", "the market", "the social system", or "the generation gap" might be tangible, material beings and not metaphorical, abstract, virtual entities? We may see in constructed realities of this kind a needed reduction of complex structures, systems, forces, agents, and actors to simple elements and linear connections under more strict levels of organisation. It is an important task for the researcher to restore in analysis and theory building the complex, chaotic nature of the biological, social and historical concrete world. Nevertheless, such theoretical devices (or models) are necessary for approaching methodologically the overwhelming complexity of the "real realities" of these disciplines..$^{1-37}$

Another interesting theoretical question for this discussion is the subject produced as effect of scientific discourses. For Foucault, modern man was invented in the 18th century as a mythical figure that, for its singularity, made possible the universalism of scientific discourses. ${ }^{16}$ Post-modern man/ woman perhaps is now being invented as a "one-dimensional man" ${ }^{17}$ determined by probabilities of events. This new being is not anymore a subject, in Foucauldian's sense, because he/ she has a non-subjective part inhabiting information networks, as proved by petty operations of daily life, as for instance a simple purchase on a credit card account or a consultation to bank automated terminals. Today, any person can buy without currency, paying anything with a magnetic card, which deduces the expenses directly from her banking account or her credit potential. However, the credit or purchasing power in fact does not belong directly to the person but refers to the other self that inhabits mass memories and circulates in networks of financial information. In the professional field, candidates to employment are checked out on their occupational history and professional references by human resources mega-databanks. In the health field, those who apply for medical insurance have the values of the premium as much as rates and treatment conditions, defined according to algorithms established for the calculation of their individual presumed health potential through estimated probabilities of getting sick, that is, their risk profiles. ${ }^{4}{ }^{18}$

Such a new man-woman, partially digital, being more and more defined by probabilities of occurrence of life events of all kinds, is different from the human being we have known for centuries. Half human and half machine, this new being has been described as a "cyborg" - "a cybernetic organism, a hybrid of machine and organism, a creature of social reality as well as a creature of fiction" (page 149). ${ }^{19}$ In epidemiological terms, what is shared with other population members, on the side of pathology, is the risk, a concept that seems to have been coined, developed, and tailored to approach the collective health of cyborgs. Indeed, the diseased body was fundamental in the historical moment of the invention of modern man, with "the birth of the clinic", the first technical discourse about the human being in modernity. ${ }^{20}$ Now, the post-modern human subject has the risk concept as a foundational element in her making as a mythical figure that has been historically constituted in current times.

In summary, with such a fertile ground provided by advanced societies structured on networks, connections, hybrids, and doubles, in an epoch that has been called post-modernity, metaphoric environments and virtual populations, with their peculiar ecology of risks, have become more and more reified. ${ }^{21}$ Reified in the sense that material existence has been given to such a virtual world, because a parallel dimension has been built, with its own conditions of production and reproduction of effects on the concrete socialhistorical life. The challenge of producing knowledge out of intangible objects, with existence in virtual realities but firmly anchored in grounded theories, has been accepted by a new generation of scientific approaches (perhaps paradigms), that have been designated as post-modern sciences. ${ }^{22}$

Defined as a privileged discourse about risk, individual and collective, epidemiology meets all requirements to become the central scientific discourse about health in post-modernity. For us, this implies accepting new roles (and also new risks). Some of the new risks may be related to the development of increasingly powerful computer systems and the use of bioinformatics techniques as simulation tools. This may give rise to "new sophists", who might reify the rhetorical power of models, using their potential for convincing people based on the assumption that they directly represent "reality".*

In such a new context, the theoretical effectiveness of the discipline depends upon a renewed inferential approachalready under construction, I do hope-flexible and more appropriate for the linkage of worlds, the real and the digital. Modern epidemiology inherited and has used two types of inference, both statistically justified, that purports to bridge analysis and reality: (a) prediction properly speaking, meaning anticipation of recurrent events in time, as related to expected new cases, and (b) generalisation, equivalent to

*I owe this important observation to a JECH anonymous reviewer. 
extrapolation to cases, events, and circumstances not included in the sample or population studied. The stochastic inference approach operates mainly to assess molecular validity (that is, generalisation from sample or study population to reference population) and to inform decision rules for patterning health-disease causal models. ${ }^{11}$

The scope of such operations is indeed quite limited. Therefore, to help overcome some of these limits, philosophical issues as well as socio-cultural and political questions must be central in the agenda of post-modern epidemiology. Now, epidemiological theory and methodology face the challenge of creating new techniques and procedures for turning concrete people into inhabitants of virtual worlds, without breaking the links with the "real reality" of population health.

\section{EPILOGUE}

A couple of remarks are needed before closing this short commentary. Firstly, epidemiology is not a monolithic or uniform science. $\dagger$ While certainly there is a mainstream "modern" epidemiology, other critical approaches (for example, social epidemiology, ecoepidemiology, etnoepidemiology, etc) have been presented in several papers recently published. Such proposals should be considered as examples of awareness of the constructed representational links of epidemiological research to the so called "real" world, which is a baseline for post-modern science. ${ }^{122}$ Secondly, and most importantly, the focus on the importance of language should not neglect the need of a profound understanding of the social and political processes of how epidemiology has historically been built.

The argument of this essay, generally speaking, is not new at all. Since Kuhn's groundbreaking work, the notion that science is socially constructed has become hegemonic in the field of "social studies of science". $\neq$ The basic assumption of such an approach is that, beyond logical foundations and methodological and thematic questions, the organised production of scientific knowledge is carried out in complex institutional networks constructed and operated by concrete historical agents, directly connected to the greater socialpolitical context. ${ }^{22-24}$ This means that science is not only material technological achievements, institutional organisation, theory building, and social practice but also places and structures such as laboratories, fields, and observatories. Reading Saramago, we come to think that such elements do form an epidemiological virtualscape and therefore they are perhaps more imaginary than we are used to imagine and more real than we are used to realise.

Several studies on the social organisation of sciences have focused researchers and laboratories engaged in biomedical research. ${ }^{26-28}$ In this spirit, it is time to open up the practice of epidemiological inquiry to become a research topic itself. Social theorists give this openness a name- "reflexivity"and unanimously regard it as a sign of maturity for any science. ${ }^{22}$ Epidemiology (hopefully inspired by Saramago's

†Again, I owe this important observation to a JECH anonymous reviewer.

‡ See Lynch (1997) ${ }^{23}$ for a historical review, Latour (1999) ${ }^{24}$ for a critical update, and Biagioli (1999) ${ }^{25}$ for a broad sampler of this field of research. Unfortunately, to my knowledge, this approach has not been used in our field and many epidemiologists might not be acquainted to the subject. masterpiece) soon will deserve to be aligned among other post-modern, mature scientific disciplines.

But science cannot be the exact mirror of reality, to the same extent that the arts are not instantaneous representation of the social imaginary nor language is the social discourse. So, perhaps we epidemiological scientists may use well the arts and literature to see ourselves and our science through the looking glass of society and culture. How to make this action part of another dream, not the methodological dream of having the perfect (natural or virtual) laboratory but the dream of being part of a politically responsible discipline, is an open question. The new epidemiological dream is having our young science deeply committed to human emancipation and social equity and justice.

\section{ACKNOWLEDGEMENTS}

The author holds a Senior (I-A) Research Fellowship Grant from the Brazilian National Research Council (Proc. 520573/95-1). Two anonymous reviewers contributed much to the final version of this paper.

Funding: none.

Conflicts of interest: none declared.

\section{REFERENCES}

1 Chalmers A. What is this thing called science? London: Open University Press, 1982.

2 Kuhn T. The road since structure. Chicago: University of Chicago Press, 2000.

3 Castoriadis C. The imaginary institution of society. Cambridge: MIT Press, 1987

4 Beck U. La Sociedad del Riesgo. In: Las concecuencias perversas de la modernidad: modernidad, contingencia y riesgo. Barcelona: Anthropos, 1996:182-201

5 Gadamer H-G. The enigma of health. Stanford, CA: Stanford University Press, 1996.

6 Knorr-Cetina K. Epistemic cultures: how the sciences make knowledge. Cambridge, MA: Harvard University Press, 1999.

7 Potter J. Representing reality: discourse, rhetoric and social construction. London: Sage, 1997.

8 Saramago J. All the names. New York: Harcourt, 2001.

9 Susser M. Epidemiology in the United States after world war II: the evolution of technique. Epidemiol Rev 1985;7:147-77.

10 White K. Healing the schism. Epidemiology, medicine, and the public's health. New York: Springer Verlag, 1991.

11 Almeida-Filho N. La Ciencia Tímida - Ensayos hacia la deconstrucción de la Epidemiología. Buenos Aires: Editorial Lugar, 2000.

12 Greenwood M. Epidemiology: historical and experimental. London: Humphrey Millford, 1932.

13 Vineis P. Modelli di Rischio - Epidemiologia e Causalitá. Torino: Einaudi, 1990.

14 Jenicek M. Epidemiology: the logic of modern medicine. Montreal: University Press, 1995.

15 Renton A. Epidemiology and causation: a realist view. J Epidemiol Community Health 1994:48:79-85.

16 Foucault M. The order of things. New York: Pantheon, 1976.

17 Marcuse H. One-dimensional man. New York: Routledge, 1968.

18 Alexander J. The ideological construction of risk: an analysis of corporate health programs in the 1980s. Soc Sci Med 1988;26:559-67.

19 Haraway DJ. Symians, cyborgs, and women. The reinvention of nature. New York: Routledge, 1991.

20 Foucault M. The birth of the clinic. New York: Pantheon, 1970.

21 Hayes M. On the epistemology of risk: language, logic and social science. Soc Sci Med 1992:35:401-7.

22 Santos BS. Introdução a uma Ciência Pós-Moderna. Rio: Graal, 2000.

23 Lynch M. Scientific practice and ordinary action. Cambridge: Cambridge University Press, 1997.

24 Latour B. Pandoras's Hope: essays on the reality of sciences studies. Cambridge, MA: Harvard University Press, 1999.

25 Biagioli M, ed. The science studies reader. New York: Routledge, 1999.

26 Latour B, Woolgar M. Laboratory life: the social construction of scientific racts.. Beverly Hills: Sage, 1979.

27 Martin E. Flexible Bodies: the role of immunity in American culture. Boston: Beacon Press, 1994.

28 Rabinow P. Making PCR. A story of biotechnology. Chicago: University of Chicago Press, 1996. 